\title{
8
}
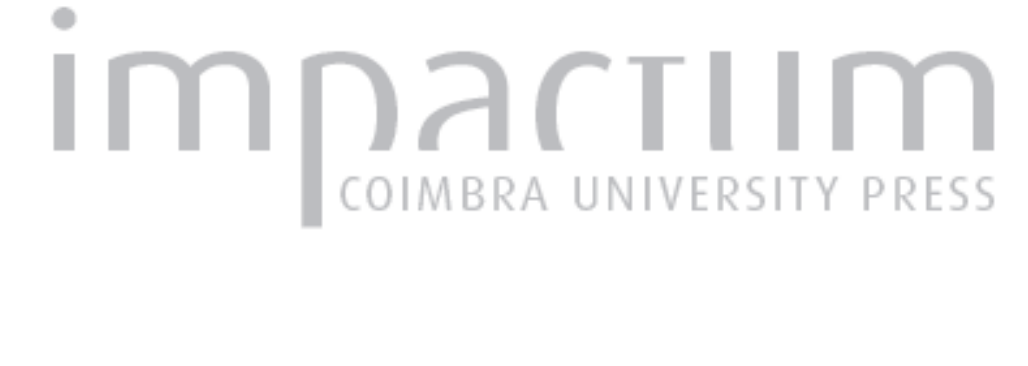

\section{Aportaciones analíticas sobre orfebrería castreña: problemas de caracterización en piezas de la colección del Museo Arqueológico Nacional (Madrid)}
Autor(es): $\quad$ García-Vuelta, Oscar; Montero-Ruiz, Ignacio
Publicado por: Faculdade de Letras da Universidade de Coimbra
URL persistente:
URI:http://hdl.handle.net/10316.2/37747
DOI:
DOI:http://dx.doi.org/10.14195/1647-8657_46_5
Accessed : $\quad$ 26-Apr-2023 12:08:01

A navegação consulta e descarregamento dos títulos inseridos nas Bibliotecas Digitais UC Digitalis, UC Pombalina e UC Impactum, pressupõem a aceitação plena e sem reservas dos Termos e Condições de Uso destas Bibliotecas Digitais, disponíveis em https://digitalis.uc.pt/pt-pt/termos.

Conforme exposto nos referidos Termos e Condições de Uso, o descarregamento de títulos de acesso restrito requer uma licença válida de autorização devendo o utilizador aceder ao(s) documento(s) a partir de um endereço de IP da instituição detentora da supramencionada licença.

Ao utilizador é apenas permitido o descarregamento para uso pessoal, pelo que o emprego do(s) título(s) descarregado(s) para outro fim, designadamente comercial, carece de autorização do respetivo autor ou editor da obra.

Na medida em que todas as obras da UC Digitalis se encontram protegidas pelo Código do Direito de Autor e Direitos Conexos e demais legislação aplicável, toda a cópia, parcial ou total, deste documento, nos casos em que é legalmente admitida, deverá conter ou fazer-se acompanhar por este aviso.

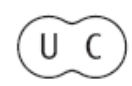




\section{CONIMBRIGA}

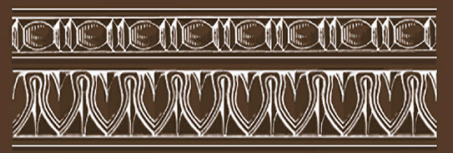

INSTITUTO DE ARQUEOLOGIA

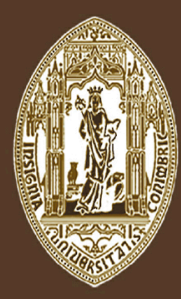

VOLUME XLVI - 2007

FACULDADE DE LETRAS UNIVERSIDADE DE COIMBRA 
OSCAR GARCÍA-VuELTA

IGNACIO MONTERo-RUIZ

Departamento de Prehistoria. Instituto de Historia. CSIC

C/Serrano 13. 28001. Madrid. España

\section{APORTACIONES ANALÍTICAS SOBRE ORFEBRERÍA CASTREÑA: PROBLEMAS DE CARACTERIZACIÓN EN PIEZAS DE LA COLECCIÓN DEL MUSEO ARQUEOLÓGICO NACIONAL (MADRID) \\ "Conimbriga" XLVI (2007) p. 89-115}

RESUMEN: se presenta el estudio analítico de 15 objetos de orfebrería castreña del Museo Arqueológico Nacional. Mediante un estudio topográfico y de composición con la técnica no destructiva de Fluorescencia de rayos X (ED-XRF) se valoran los rasgos de taller y tecnológicos de estas producciones. La diversidad en la composición de los diferentes elementos estructurales se revela como un elemento destacado. Esta diversidad no fue tenida en cuenta en estudios anteriores y obliga a una investigación más detallada sobre cada objeto. Se incluyen comentarios sobre los problemas comparativos de los estudios analíticos.

PALABRAS ClAVE: arqueometalurgia, arqueología del oro, orfebrería castreña, torques, análisis por fluorescencia de rayos X.

ABSTRACT: this paper deals with the analytical study of 15 Castro Culture gold objects from the National Archaeological Museum in Madrid. Topographic study and non destructive ED-XRF analysis give us new information about workshops and technological features of the gold production. Diversity of composition in structural elements is shown. This feature makes necessary a more detailed study of each object and it was not taking into account in previous work on Castro jewellery. Comments about problems in comparative elemental analysis are given.

KeYwords: archaeometallurgy, Gold Archaeology, Castro-culture jewellery, torcs, X-Ray Fluorescence analysis. 
(Página deixada propositadamente em branco) 


\section{APORTACIONES ANALÍTICAS SOBRE ORFEBRERÍA CASTREÑA:}

\section{Problemas de caracterización en Piezas de la Colección del Museo Arqueológico Nacional (Madrid)}

\section{Introducción}

La orfebrería constituye una de las manifestaciones materiales más destacadas y complejas de las poblaciones de la II. ${ }^{a}$ Edad del Hierro del Noroeste peninsular. Su estudio plantea todavía importantes cuestiones abiertas, en buena medida estrechamente vinculadas con los principales debates existentes en la investigación sobre estas sociedades (Fernández-Posse, 1998). Entre estos temas, pueden destacarse los relativos a la adecuada periodización y análisis contextual de los materiales, o a la interpretación de su significado a lo largo del tiempo (Perea, 2003).

A grandes rasgos se acepta que la orfebrería del ámbito castreño tiene sus raíces en el Bronce Final, con un desarrollo a lo largo de la Edad del Hierro y una perduración hasta momentos posteriores al cambio de Era (Peña, 1996). A lo largo de todo este tiempo, asumió tanto una larga tradición local del trabajo del oro como influencias externas, principalmente mediterráneas, que se reflejan en las técnicas de fabricación y ornamentación empleadas, como la filigrana y el granulado (López Cuevillas, 1951; Blanco, 1957; Pérez Outeiriño, 1982; Perea, 1991; Armbruster y Perea, 2000).

Sin duda, una de las características que mejor definen a esta orfebrería es el uso del oro como material básico de fabricación, empleándose en menor medida metales como la plata o el bronce, al contrario de lo que sucede en otras regiones peninsulares durante el mismo período (Raddatz, 1969; Nicolini, 1990; Perea, 1991; Montero y Rovira, 1991). Actualmente se acepta una utilización mayoritaria de oros aluviales como materia prima, obtenidos mediante la técnica del bateo, ya 
que la explotación en mina parece iniciarse en época romana (Sánchez-Palencia, 1997; Sánchez-Palencia y Fernández-Posse, 1998).

Como se ha señalado, muchas de las producciones de la orfebrería castreña se caracterizan por un cierto conservadurismo formal, que contrasta con la variabilidad documentada en los procesos de fabricación de los principales grupos de materiales (Armbruster y Perea, 2000). Entre los tipos más representativos destacan los adornos rígidos de cuello o torques, definidos por aros en forma de $\mathrm{C}$ con terminales voluminosos en sus extremos. Se documentan también diversos grupos de arracadas, brazaletes, collares articulados, broches y colgantes, junto a otros objetos de interpretación funcional más dudosa, como diademas-cinturón, posibles adornos de pelo, o varias clases de apliques y revestimientos (López Cuevillas, 1951; Monteagudo, 1952; Silva, 1986; Maya, 1987-1988; Pérez Outeiriño, 1982, 1989 y 1990; Prieto, 1996; García Vuelta y Perea, 2001).

Transcurrido más de un siglo de investigaciones, los trabajos dedicados al estudio de la tecnología de esta orfebrería han ocupado un lugar secundario respecto a los centrados en el análisis de la adscripción territorial o cultural de los objetos, o a su sistematización formal y tipológica. A grandes rasgos, pueden establecerse fundamentalmente tres direcciones en las aportaciones sobre tecnología. En primer lugar, las centradas en el estudio de los recursos y modos de obtención y preparación de la materia prima (Vázquez Varela, 1995; Sánchez-Palencia, 1996 y 1997; Sánchez-Palencia y Fernández-Posse, 1998; Pérez Outeiriño, 1992). En segundo lugar, los estudios que tratan de caracterizar los procedimientos y técnicas empleadas en la elaboración de los distintos grupos de materiales (Pérez Outeiriño, 1982; Nicolini, 1990; Armbruster, 1998 y 2000; Armbruster y Perea, 2000 y 2001; García Vuelta, 2003; Perea, 1991 y 2003). Finalmente, los trabajos centrados en el análisis de las aleaciones con las que se fabricaron estos objetos (Hartmann, 1971 y 1982; Perea et al., 1991; Montero y Rovira, 1991; Pingel, 1992; Alves et al., 2002; Monge et al., 2004).

La mayor parte de los datos analíticos disponibles para el conocimiento de las aleaciones castreñas proceden de las actuaciones realizadas en el seno del ambicioso proyecto alemán Studien zu den Anfängen der Metallurgie (SAM). Parte de los resultados del equipo de Stuttgart sobre piezas de la Península Ibérica, obtenidos mediante el uso de espectroscopía óptica de emisión (OES), fueron publicados por A. Hartmann (1971 y 1982). 
De forma posterior, el volumen de información se ha incrementado con aportaciones puntuales, derivadas fundamentalmente de la aparición de nuevos hallazgos, o de los objetivos concretos de determinados proyectos de investigación. Por desgracia, no todos los estudios realizados hasta la fecha han sido objeto de una adecuada publicación. Podemos señalar por ejemplo los análisis de arracadas como la de Baroña (Calo y Soeiro, 1986), los de torques procedentes de Sanfins, en Paços de Ferreira (Silva, 1986) u Orbellido, en A Coruña (Casal y Acuña, 1984-1985), los de varias tortas o lingotes plano-convexos de Galicia procedentes de Castromao, Troña o Corvazal (Pérez Outeiriño, 1992), o los de algunos fragmentos de diademas-cinturón de Moñes, Asturias (Eluère, 1986-1987; Perea et al., 2003).

Entre los trabajos más recientes pueden mencionarse los análisis de varios colgantes de la colección del Instituto Valencia de Don Juan, desde el Dpto. de Prehistoria del CSIC, o los de restos de crisoles del castro de Chao Samartín, Grandas de Salime, Asturias (Villa, 2004), aún en fase de publicación, así como los estudios del torques de Santiago de Xubial, A Coruña (Almagro Gorbea et al., 2004) y del torques portugués de Chaves, en este caso mediante PIXE y XRF (Alves et al., 2002; Monge et al., 2004).

El principal objetivo de este trabajo es dar a conocer un nuevo grupo de resultados analíticos obtenidos en 2004-2005 sobre un grupo de 15 piezas de orfebrería castreña conservadas en el Museo Arqueológico Nacional de Madrid (M.A.N.). Se trata concretamente de dos fragmentos de un torques procedente supuestamente de Cangas de Onís, en Asturias (Álvarez-Ossorio, 1931 y 1954; López Cuevillas, 1951; García Vuelta, 2001), 5 torques de oro procedentes de A Madorra (Cospeito, Lugo), uno de plata de Sobrado dos Monxes (A Coruña) y 6 torques de oro y una pareja de anillas estampadas entrelazadas, de procedencia dudosa (Ladra, 1996 y 1997-1998; Barril y Rodero, 2002; García Vuelta, 2000 y e.p.).

Este estudio, que completa el repertorio de datos disponible sobre esta importante colección, se ha basado en un análisis no destructivo de los objetos por ED-XRF. Con la excepción del ejemplar del lote de Cangas de Onís, previamente analizado por A. Hartmann (1982: SAM 1843, 1844 y 1846), carecíamos hasta el momento de informaciones relativas a la composición del resto de los materiales, que fueron adquiridos por el M.A.N. a principios de los años 70 (Archivo M.A.N., expedientes 1972/64 y 1972/113). 


\section{Metodología}

La labor realizada se desarrolló a partir de un trabajo previo que podemos dividir en dos fases. En primer lugar, una revisión historiográfica y documental que se realizó principalmente en el Archivo Documental del MAN. En segundo lugar, un estudio topográfico de las piezas mediante su observación con microscopio binocular, para definir y caracterizar sus elementos estructurales y ornamentales e identificar, a partir de las huellas de trabajo observables, cuales fueron las técnicas y procedimientos empleados en su fabricación. Se ha perseguido además en este apartado registrar otras características, como posibles reparaciones o huellas de uso en los objetos. Para ello, hemos empleado dos lupas binoculares de 20 y $60 \mathrm{X}$, documentando los resultados mediante fotografía macro (García Vuelta, e.p.) ${ }^{1}$.

La siguiente fase de trabajo, iniciada a finales de 2004, se ha centrado en el estudio analítico de los objetos. Hemos utilizado para ello la técnica de Espectrometría de Fluorescencia de rayos X en dispersión de energía (ED-XRF), empleando un espectrómetro METOREX X-MET 920MP dotado con detector de $\mathrm{Si}(\mathrm{Li})$ y fuentes de Americio-Cadmio, ubicado en el Museo Arqueológico Nacional (Madrid) ${ }^{2}$.

Estos análisis se han realizado en todos los casos a partir de las cuestiones planteadas en el estudio topográfico previo, y han tenido en cuenta los diferentes elementos estructurales y ornamentales documen-

1 Esta labor, que se ha extendido a toda la colección de orfebrería castreña del M.A.N., se inició con la concesión a uno de nosotros de una Beca en Proyectos de Investigación en materia museística en el Dpto. de Protohistoria y Colonizaciones del M.A.N. (García Vuelta, 2000), y continuó posteriormente desde los Programas de Investigación realizados desde el Proyecto AU en el Dpto. de Prehistoria del CSIC, dirigidos por la Dra. A. Perea (Armbruster y Perea, 2000; García Vuelta, 2001; García Vuelta y Perea, 2001). Nuevamente agradecemos al Dpto. de Restauración y al Gabinete Numismático del M.A.N. las facilidades prestadas para el estudio de los objetos.

2 Estos análisis, con un total de 49 muestras realizadas, fueron efectuados entre diciembre de 2004 y febrero de 2005 y se integran en el Programa de Investigación "Arqueometalurgia de la Península Ibérica", formando parte de los trabajos realizados en el Grupo de Investigación Historia de la Tecnología. Arqueometalurgia del Departamento de Prehistoria del Instituto de Historia (CSIC). Agradecemos al Departamento de Protohistoria y Colonizaciones del M.A.N. las facilidades y colaboración prestadas en todo momento para este trabajo. 
tados. Se han considerado igualmente las posibles ventajas y limitaciones del método y el equipo empleados. Entre las primeras, hay que señalar que no ha sido posible aportar un estudio pormenorizado de todas las zonas y elementos de interés considerados, debido a la morfología de las piezas y el tamaño de la ventana del analizador, que impide un microanálisis. Hay que señalar también algunas limitaciones en cuanto a la capacidad de identificación de los elementos traza, pues el equipo disponible carece de precisión suficiente para detectar proporciones inferiores al 0,1-0,3\%, según cada elemento ${ }^{3}$.

Frente a estos inconvenientes, el método empleado ofrece sin embargo una importante ventaja respecto a otro tipo de estudios, como los realizados con Microsonda en Microscopia Electrónica de Barrido, la capacidad de poder trabajar con piezas de cualquier tamaño y morfología "al aire". El sistema utilizado hace posible además el estudio analítico sin extracción de muestras de los objetos. Esta posibilidad ha facilitado la consideración y muestreo de los principales elementos estructurales de los objetos - no tenidos en cuenta en la mayoría de los trabajos previos (Hartmann 1982) -, permitiendo aportar, a la espera de una caracterización analítica más exahustiva, algunas interesantes conclusiones acerca de su tecnología.

Los datos que se presentan se han obtenido en todos los casos sobre la superficie de las piezas, seleccionando aquellas zonas más adecuadas, por su geometría, a la ventana y la disposición de los detectores del equipo empleado. Los resultados se han expresado en valores de $\%$ en peso, cuantificando únicamente los elementos mayoritarios y minoritarios.

\section{Catálogo de materiales analizados}

Como se ha señalado, la muestra considerada incluye un total de 15 objetos, 12 torques de oro (uno de ellos incompleto), 2 anillas de oro entrelazadas, y un torques de plata. A continuación exponemos una breve descripción de los materiales, que se organizan en función de sus

3 Aunque los límites teóricos de detección se sitúan en torno al 0,01\% en la mayoría de los elementos, en la práctica el ruido de fondo impide lecturas fiables tan detalladas. 
hallazgos o lotes de adscripción. Los datos relativos a las medidas básicas y peso de cada ejemplar se exponen en la tabla $n .^{\circ} 1$.

\subsection{Grupo de 5 torques de oro del hallazgo de A Madorra, Pazo de Pumares, Cospeito, Lugo (Inventarios 1972/64/1 a 1972/64/5)}

Adquiridos en 1972 previa oferta de D. Manuel Lousa, que los declaró procedentes de un hallazgo producido probablemente a finales del S. XIX en el lugar de A Madorra, en Pazo de Pumares, Cospeito, Lugo (Archivo M.A.N., expediente 1972/64; Ladra, 1996 y 1997-98). Durante el proceso oficial de compra no se recabaron datos adicionales sobre el contexto o circunstancias de recuperación de estas piezas, que han sido consideradas como un conjunto arqueológico (inventarios 1972/64/1 a 5).

Descripción:

- Inventario: 1972/64/1. (Est. I, 1): torques con aro macizo de sección circular, cuyo grosor se adelgaza hacia los extremos. Los laterales del aro están recubiertos con tramos de alambre enrollado, que ocupan cuatro quintas partes de su desarrollo; la zona central se decoró con filigrana, dispuesta en cuatro bandas longitudinales formadas por cordones y ondas entrelazadas. Los terminales, de pequeño tamaño, son macizos y presentan perfil en doble escocia.

- Inventario 1972/64/2. (Est. I, 2): torques con aro macizo de sección circular, cuyo grosor se adelgaza hacia los extremos. Los laterales del aro presentan tramos de finos alambres enrollados; la zona central incluye una decoración de filigrana dispuesta en bandas longitudinales de cordones y ondas entrelazadas. Los terminales de esta pieza, macizos, presentan perfil en doble escocia.

- Inventario 1972/64/3. (Est. I, 3): torques de morfología muy similar al número 2 de este lote, incluyendo los mismos elementos estructurales. Se encuentra ligeramente deformado en uno de sus laterales ${ }^{4}$.

4 Un torques similar a las piezas $1972 / 64 / 2$ y 3, y en particular a esta última, de propiedad particular, fue publicado por F. Bouza en 1965, como procedente de un 
- Inventario 1972/64/4. (Est. I, 4): torques con aro macizo de sección cuadrada-romboidal adelgazada hacia los extremos. El aro presenta decoración en el tercio central de una de sus caras, formada por series de triángulos y líneas paralelas elaboradas con motivos circulares estampados. El perfil de los terminales, macizos, forma una escocia y un tronco de cono (Ladra, 1997-1998: 69), aunque la pieza se ha integrado dentro del grupo de torques con terminales en doble escocia (Armbruster y Perea, 2000).

- Inventario 1972/64/5. (Est. I, 5): torques de influencia meseteña, que incluye un aro formado por varios elementos independientes. Su zona central, de desarrollo funicular, se fabricó mediante la colocación de varios tramos de alambre de sección cóncavo convexa y circular enrollados sobre un alma interior, formando una decoración plástica de tres dobles lazos de sección circular. Los extremos del torques, macizos, presentan decoración estampada e incluyen pequeños terminales vueltos al exterior, en forma de cilindro estrangulado con punta redondeada.

\subsection{Torques de plata de Sobrado dos Monxes, A Coruña (Inventario 1972/64/6)}

Esta interesante pieza, atípica en el ámbito castreño por su material de fabricación, fue vendida al M.A.N. junto con los torques A Madorra en 1972. Durante las gestiones de adquisición se señaló como punto de hallazgo "un lugar de la Sierra de Sobrado de los Monjes", en la provincia de A Coruña. En algunos documentos conservados en el Archivo del M.A.N. se sugiere su descubrimiento a finales del siglo

hallazgo de características desconocidas ocurrido probablemente en la provincia de Lugo a finales del siglo XIX (Bouza, 1965: 5-7, n. ${ }^{\circ} 3$ ). Dicho ejemplar, para el que se señaló un peso de 193 gramos, habría pasado por las manos de varios propietarios hasta ser adquirido en la ciudad de Vigo entre 1910 y 1914, indicando su poseedor como posibles lugares de hallazgo Valadouro y Foz (Bouza, 1965: 6). Hay que señalar que el mismo personaje, cuya identidad no fue revelada, poseía también en esta fecha otros dos torques adquiridos junto a éste, uno de los cuales podría identificarse con el n. ${ }^{\circ}$ 1972/113/6 de este catálogo (Vid. infra). 
XIX, sin que posteriormente hayan sido publicados nuevos datos sobre las circunstancias de hallazgo (Archivo M.A.N., expediente 1972/64; Ladra, 1996 y 1997-98).

Descripción:

- Inventario: 1972/64/6 (Est. I, 6): torques con aro macizo de sección cuadrada-romboidal cuyo grosor se adelgaza progresivamente hacia los extremos. Presenta terminales en doble escocia, probablemente huecos, con paredes gruesas.

\subsection{Grupo de 6 torques de oro y pareja de anillas de procedencia incierta (Inventarios 1972/113/1 a 1972/113/8)}

Este lote, formado por 6 torques (1972/113/1 a 6) y una pareja de anillas entrelazadas de oro (1972/113/7 y 8) fue vendido al M.A.N. en 1972, efectuando la oferta inicial de las piezas D. Manuel Lousa. Hasta la fecha, carecemos de datos sobre el lugar de recuperación de los objetos, que hay que localizar muy probablemente en el área gallega, así como sobre su contexto o posibles asociaciones (Archivo M.A.N., expediente 1972/113).

Descripción:

- Inventario 1972/113/1. (Est. II, 1): torques con aro macizo de sección circular adelgazada hacia los extremos. Incluye tramos de alambre enrollado sobre los laterales, delimitados hacia la parte central, exenta de decoración, por dos parejas de dobles espirales en filigrana a cada lado. La pieza presenta terminales macizos con perfil en doble escocia, ligeramente moldurados en sus caras frontal y posterior.

- Inventario 1972/113/2. (Est. II, 2): torques de pequeño tamaño o posible brazalete, que presenta sección mixta, cuadrada romboidal en la zona central y circular en la parte próxima a los extremos. La pieza está decorada con incisiones paralelas, dispuestas en dos grupos de dos y tres líneas en los tramos laterales del aro. Incluye terminales vueltos al exterior, en forma de cilindro estrangulado con punta redondeada y parte posterior moldurada, muy semejantes a los del torques $n .{ }^{\circ} 5$ del conjunto de A Madorra. 
- Inventario 1972/113/3. (Est. II, 3): torques con aro macizo de sección cuadrada romboidal adelgazada del centro hacia los extremos, y terminales en doble escocia, macizos. El aro está decorado en la parte central de su desarrollo con series de motivos geométricos circulares estampados.

- Inventario 1972/113/4. (Est. II, 4): ejemplar de reducidas dimensiones, que podríamos interpretar como un torques de reducidas dimensiones o como un adorno de brazo. La pieza, que no presenta decoración, incluye un aro macizo de acabado irregular, con sección circular, cuyo grosor se adelgaza ligeramente hacia los extremos y terminales macizos en doble escocia.

- Inventario 1972/113/5. (Est. II, 5): torques con aro macizo de sección cuadrada-romboidal y remates en doble tronco de cono, también macizos, moldurados en sus caras frontal y posterior.

- Inventario 1972/113/6. (Est. II, 6): torques con aro macizo de sección cuadrada-romboidal adelgazada hacia los extremos y terminales piriformes voluminosos, con punta truncada, probablemente macizos, aunque no descartamos que pudiese tratarse de terminales huecos de paredes gruesas. Se trata de una pieza muy semejante a uno de los tres torques $\left(n .^{\circ} 1\right)$ publicados por F. Bouza en 1965, en este caso con una procedencia dudosa de Valadouro, Mondoñedo, pudiendo tratarse probablemente del mismo objeto (Bouza, 1965: 5-7, fig. 1; Ladra, 1997-1998: 71) 5 .

- Inventarios 1972/113/7 y 1972/113/8 (Est. III, Fig. 1): pareja de anillas de oro abiertas de interpretación funcional dudosa. Presentan sección circular en su zona central y rectangular-cuadrangular en sus extremos, que se encuentran ligeramente solapados entre sí en los dos ejemplares. Las anillas se conservan entrelazadas, no siendo posible su separación sin deformar el metal, y ofrecen la particularidad de incluir series de motivos triangulares enfrentados estampados en dos de sus caras, observándose huellas de retoque por martillado en su superficie.

5 Este ejemplar se encontraba en propiedad particular en el momento de la publicación de F. Bouza, habiendo pertenecido previamente a varias colecciones. Bouza sitúa el posible momento de hallazgo de los tres torques que presenta a finales del siglo XIX (Bouza, 1965: 5). Otra de las piezas publicadas por el autor, como ya se ha indicado, es muy semejante al torques n. ${ }^{\circ}$ 1972/64/3 de este catálogo (Vid. supra). 


\subsection{Fragmentos de aro y terminal de un torques con procedencia su- puesta de Cangas de Onís, Asturias (Inventarios 33.133 y 33.138).}

Forman parte de un lote que integra 8 fragmentos de aros y terminales de torques - pertenecientes al menos a tres ejemplares incompletos - y una diadema/cinturón (M.A.N., inventarios 33.132 a 33.139). Las piezas, que habían pertenecido al coleccionista asturiano Sebastián de Soto Cortés antes pasar al mercado de antigüiedades, fueron ofertadas al Museo a finales de 1930, siendo definitivamente adquiridas en 1931 (Archivo M.A.N., expedientes 1930/111 y 1931/11).

La procedencia de los objetos, tradicionalmente interpretados como un conjunto arqueológico a pesar de la falta de datos, se estableció en Cangas de Onís, debido al testimonio de su vendedor, M. Ruíz (Álvarez-Ossorio, 1931 y 1954). Sin embargo, esta información podría obedecer al lugar en donde se afincó la colección Soto ${ }^{6}$ desconociéndose en realidad sus circunstancias de hallazgo, cuya ubicación parece situarse en Asturias (Maya, 1987-1988; García Vuelta, 2001 y e.p.).

Los dos fragmentos analizados pertenecen a un mismo ejemplar, del que se conserva un tercer fragmento (inv. 33.137), constituyendo el único ejemplo de la muestra que cuenta con análisis de composición previos (Hartmann, 1982: SAM 1846, 1843 y 1844).

\section{Descripción:}

- Inventario: 33.133, 33.137 y 33.138. (Est. III, Fig. 2): torques incompleto y fragmentado, del que se conserva parte de la zona central y uno de los laterales del aro (inv. 33.133), así como los dos terminales, uno de los cuales incluye parte del aro (García Vuelta, 2001).

El fragmento 33.133 incorpora una barra interior fabricada con una aleación de plata, oro y cobre, actualmente de sección rectangular en sus extremos, que originalmente fue recubierta con diferentes elementos áureos; sobre sus tercios laterales se colocaron tramos de alambres enrollados de sección cóncavo-convexa, asegurados mediante puntos de soldadura. La parte central del aro quedó recubierta a su vez por un tubo o placa, decorado en su parte exterior con series de motivos geométricos

6 Emplazada en un palacete en la localidad de Labra, muy próxima a la de Cangas de Onís (Somoano, 1960). 
dispuestos en bandas longitudinales separadas entre sí por junquillos en resalte. Sobre las zonas de contacto entre los tramos de alambres y el tubo central, se soldaron placas ornamentales con dobles espirales de filigrana con botón central sobre fondo granulado, elaboradas a la cera perdida.

Los terminales del torques, con perfil en doble escocia, son huecos y se fabricaron mediante la soldadura de cuatro elementos independientes; dos cuerpos centrales unidos por su ecuador y dos discos de cierre fabricados a la cera perdida, ambos decorados con motivos geométricos en disposición concéntrica, rematándose los frontales con un glóbulo central. Ambos terminales incluyen un pequeño orificio en el cuerpo central posterior, realizado probablemente para facilitar el proceso de soldadura de sus elementos (Armbruster y Perea, 2000; García Vuelta, 2001).

TABLA 1 - Dimensiones y medidas de los materiales en estudio

\begin{tabular}{|c|c|c|c|c|c|c|c|}
\hline \multicolumn{8}{|c|}{ Torques } \\
\hline \multirow[b]{2}{*}{ Inventario } & \multirow{2}{*}{$\begin{array}{c}\varnothing \\
\max .\end{array}$} & \multicolumn{2}{|c|}{ Espesor aro } & \multicolumn{3}{|c|}{ Terminales } & \multirow[b]{2}{*}{ Peso (gr.) } \\
\hline & & $\max$. & $\min$. & Long. 1 & Long. 2 & Grosor max. & \\
\hline 1972/64/1 & 11,7 & 0,75 & 0,55 & 1,40 & 1,45 & 1,35 & 184,0 \\
\hline $1972 / 64 / 2$ & 15,0 & 0,80 & 0,50 & 2,30 & 2,35 & 2,0 & 219,0 \\
\hline $1972 / 64 / 3$ & 13,5 & 0,85 & 0,50 & 1,85 & 1,95 & 1,75 & 177,4 \\
\hline $1972 / 64 / 4$ & 12,0 & 0,70 & $0,25 ?$ & 1,5 & 1,5 & 1,0 & 145,3 \\
\hline $1972 / 64 / 5$ & 15,3 & 0,8 & 0,4 & 1,47 & 1,47 & 0,5 & 228,5 \\
\hline 1972/64/6 & 15,5 & 0,85 & 0,55 & 2,2 & 2,0 & 2,3 & 220,0 \\
\hline 1972/113/1 & 15,1 & 0,8 & 0,55 & 2,8 & 2,8 & 2,0 & 371,5 \\
\hline $1972 / 113 / 2$ & 8,5 & 0,4 & 0,25 & 1,7 & 1,8 & 0,4 & 69,46 \\
\hline 1972/113/3 & 14,6 & 0,7 & 0,4 & 2,4 & 2,5 & 2 & 257,0 \\
\hline 1972/113/4 & 9,7 & 0,65 & 0,55 & 1,9 & 1,8 & 1,7 & 148,4 \\
\hline $1972 / 113 / 5$ & 15,6 & 1,0 & 0,7 & 2,9 & 3,1 & 2,5 & 474,0 \\
\hline $1972 / 113 / 6$ & 13,4 & 0,8 & 0,6 & 3,4 & 3,2 & 2,5 & 257,7 \\
\hline \multicolumn{8}{|c|}{ Anillas } \\
\hline $1972 / 113 / 7$ & 3,35 & 0,6 & & & & & \multirow{2}{*}{63,5} \\
\hline 1972/113/8 & 3,2 & 0,5 & & & & & \\
\hline
\end{tabular}

\section{Los resultados analíticos. Discusión}

El primer rasgo a destacar del conjunto de análisis realizado (tabla 2), es la clara diferencia existente entre la composición de las dos anillas estampadas 1972/113/7 y 1972/113/8 respecto el resto de torques áureos. Ambas son oros aleados con un porcentaje bajo en plata (5-6\%) y sin cobre (Tab. 2, PA11680 y PA11681). 
TABLA 2 - Análisis por ED-XRF

\begin{tabular}{|c|c|c|c|c|c|c|}
\hline Inventario & Tipo & ELEMENTO Y ZONA ANALIZADA & Au & Ag & $\mathbf{C u}$ & Análisis \\
\hline $1972 / 113 / 1$ & Torques & Aro & 82,83 & 17,2 & nd & PA11695d \\
\hline 1972/113/1 & Torques & Aro / Alambre enrollado (a) & 81,63 & 18,0 & 0,4 & PA11695c \\
\hline $1972 / 113 / 1$ & Torques & Aro / Alambre enrollado (b) & 83,52 & 16,1 & 0,4 & PA11695f \\
\hline $1972 / 113 / 1$ & Torques & Aro / Decoración Filigrana. Espiral (a) & 81,37 & 16,6 & 2,0 & PA11695e \\
\hline $1972 / 113 / 1$ & Torques & Terminal (a) & 81,24 & 16,6 & 2,1 & PA11695a \\
\hline $1972 / 113 / 1$ & Torques & Terminal (b) & 82,66 & 15,8 & 1,5 & PA11695b \\
\hline $1972 / 113 / 2$ & Torques o Brazalete & Aro & 82,72 & 16,4 & 0,9 & PA11673b \\
\hline $1972 / 113 / 2$ & Torques o Brazalete & Terminal (a) & 84,87 & 14,8 & 0,7 & PA11673a \\
\hline $1972 / 113 / 3$ & Torques & Aro & 82,10 & 16,9 & 1,0 & PA11683b \\
\hline $1972 / 113 / 3$ & Torques & Terminal (a) & 84,74 & 14,6 & 0,7 & PA11683a \\
\hline $1972 / 113 / 4$ & Torques o Brazalete & Aro & 81,31 & 18,7 & nd & PA11687c \\
\hline $1972 / 113 / 4$ & Torques o Brazalete & Terminal (a) & 86,57 & 13,7 & nd & PA11687a \\
\hline $1972 / 113 / 4$ & Torques o Brazalete & Terminal (b) & 83,75 & 16,3 & nd & PA11687b \\
\hline $1972 / 113 / 5$ & Torques & Aro & 82,82 & 17,2 & nd & PA11682b \\
\hline $1972 / 113 / 5$ & Torques & Terminal (a) & 84,77 & 15,1 & 0,1 & PA11682a \\
\hline $1972 / 113 / 5$ & Torques & Terminal (b) & 81,46 & 17,1 & 1,5 & PA11682c \\
\hline $1972 / 113 / 6$ & Torques & Aro & 84,52 & 15,5 & nd & PA11686c \\
\hline $1972 / 113 / 6$ & Torques & Terminal (a) & 84,75 & 15,1 & 0,1 & PA11686a \\
\hline $1972 / 113 / 6$ & Torques & Terminal (b) & 86,32 & 13,4 & 0,3 & PA11686b \\
\hline $1972 / 113 / 7$ & Anilla & Aro & 94,44 & 5,6 & nd & PA11680 \\
\hline $1972 / 113 / 8$ & Anilla & Aro & 93,77 & 6,2 & nd & PA11681 \\
\hline $1972 / 64 / 1$ & Torques & Aro / Alambre enrollado (a) & 81,35 & 17,9 & 0,7 & PA11672b \\
\hline $1972 / 64 / 1$ & Torques & Aro / Decoración Filigrana & 81,32 & 17,8 & 0,9 & PA11672c \\
\hline $1972 / 64 / 1$ & Torques & Terminal (a) & 86,30 & 13,7 & nd & PA11672a \\
\hline $1972 / 64 / 2$ & Torques & Aro / Alambre enrollado (a) & 80,74 & 19,3 & nd & PA11694c \\
\hline $1972 / 64 / 2$ & Torques & Aro / Alambre enrollado (a) & 81,33 & 18,7 & nd & PA11694d \\
\hline $1972 / 64 / 2$ & Torques & Aro / Alambre enrollado (b) & 80,31 & 19,4 & 0,3 & PA11694e \\
\hline $1972 / 64 / 2$ & Torques & Aro / Decoración filigrana & 79,98 & 19,7 & 0,3 & PA11694f \\
\hline $1972 / 64 / 2$ & Torques & Terminal (a) & 84,17 & 15,8 & nd & PA11694a \\
\hline $1972 / 64 / 2$ & Torques & Terminal (b) & 82,55 & 17,4 & nd & PA11694b \\
\hline $1972 / 64 / 3$ & Torques & Aro / Alambre enrollado (a) & 80,56 & 19,3 & 0,2 & PA11684b \\
\hline $1972 / 64 / 3$ & Torques & Aro / Filigrana & 80,83 & 18,7 & 0,5 & PA11684c \\
\hline $1972 / 64 / 3$ & Torques & Terminal (a) & 81,50 & 18,5 & nd & PA11684a \\
\hline $1972 / 64 / 4$ & Torques & Aro & 85,83 & 13,9 & 0,3 & PA11693c \\
\hline $1972 / 64 / 4$ & Torques & Terminal (a) & 84,10 & 15,5 & 0,3 & PA11693a \\
\hline $1972 / 64 / 4$ & Torques & Terminal (b) & 78,13 & 21,1 & 0,7 & PA11693b \\
\hline $1972 / 64 / 5$ & Torques & Aro / Extremos (a) & 79,12 & 20,9 & nd & PA11674a \\
\hline $1972 / 64 / 5$ & Torques & Aro / Zona central (b) & 81,27 & 18,2 & 0,3 & PA11674b \\
\hline $1972 / 64 / 6$ & Torques & Aro & 1,40 & 89,2 & 9,4 & PA11685b \\
\hline $1972 / 64 / 6$ & Torques & Terminal & 1,6 & 89,1 & 9,9 & PA11685a \\
\hline 33.133 & Torques & Aro / Placa espirales & 68,35 & 30,4 & 1,2 & PA11823e \\
\hline 33.133 & Torques & Aro / Tubo central decorado & 53,56 & 41,3 & 5,2 & PA11823d \\
\hline 33.133 & Torques & Aro / Sección barra interior & 38,02 & 44,9 & 17,0 & PA11823b \\
\hline 33.133 & Torques & Aro / Sección barra interior & 37,14 & 46,5 & 16,4 & PA11823c \\
\hline 33.133 & Torques & Aro / Sección barra interior & 29,38 & 57,5 & 13,2 & PA11823a \\
\hline 33.133 & Torques & Aro / Tramo alambre enrollado & 65,35 & 32,6 & 2,1 & PA11823f \\
\hline 33.137 & Torques & Terminal / Cuerpo intermedio-frontal & 64,64 & 34,7 & 0,6 & PA11824b \\
\hline 33.137 & Torques & Terminal / Disco frontal decorado & 73,56 & 26,2 & 0,2 & PA11824a \\
\hline 33.137 & Torques & Terminal / Restos alambre enrollado & 55,92 & 41,5 & 2,5 & PA11824c \\
\hline
\end{tabular}

$($ nd $=$ no detectado $)$ 
Estas composiciones son un tanto atípicas en la orfebrería castreña y en la orfebrería del Norte peninsular en general (Montero y Rovira, 1991: 16-18), aunque no pueden considerarse excepcionales, ya que algunas piezas castreñas, como las dos pertenecientes al conjunto de Vega de Ribadeo - una diadema/cinturón y un broche - de la colección del M.A.N. se encuadran en ese rango de porcentajes de plata, con una presencia de cobre inferior al 1\% (Hartmann, 1982: SAM 1848 y 1858).

Aceptando a priori la vinculación de estas anillas a la cultura castreña, la mayor pureza de composición en oro observada no permite establecer afirmaciones taxativas sobre su funcionalidad, no descartándose la hipótesis de su posible uso como material en bruto o lingotes (García Vuelta, 2000). Sin embargo, tanto la falta de paralelos conocidos en el área como las estampaciones de sus extremos, que podrían interpretarse como decoración o posibles marcas de comprobación del metal, hacen que esta hipótesis deba manejarse con precaución.

El resto de objetos de oro analizados presenta contenidos de plata superiores al 13\%, con un rango de variación muy amplio en el que pueden diferenciarse dos grupos. Por un lado, las piezas con porcentajes de plata comprendidos entre el 13-20\%, donde se encuadran la mayoría de las muestras, y por otro las que superan el $25 \%$ de plata en su composición, perteneciendo estas últimas al torques del lote de Cangas de Onís (Est. IV, Fig. 1).

Hay que destacar que el fragmento correspondiente al aro de este ejemplar (inventario 33.133), se singulariza además por presentar unos altos porcentajes de cobre $(>5 \%)$, que no se detectan en el resto de las piezas analizadas en esta serie (Est. IV, Fig. 2), pero si en otros materiales castreños estudiados por Hartmann.

A diferencia del resto de la muestra, el aro interior de esta pieza es en realidad una aleación de plata con oro, ya que el elemento mayoritario es la plata, oscilando el oro entre el 30-40\% (Tab. 2, PA11823 a-c) $)^{7}$.

7 En anteriores trabajos se señaló la presencia de un alma interior argéntea en su aro, visible en los extremos del fragmento 33.133, que fue recubierta con otros elementos - tramos de alambres enrollados en los laterales, una placa o tubo hueco en la parte central y placas de dobles espirales sobre las zonas de contacto de los anteriores - quedando originalmente disimulada a la vista (García Vuelta, 2001). Posteriormente, otros estudios insinuaron su fabricación con una aleación baja de oro, tras realizarse una limpieza parcial de la pátina de la sección del fragmento (Moreno y Dávila, 2002: 132- 
Los resultados obtenidos sobre el aro confirman también la diferente naturaleza de los elementos que conforman la pieza; la barra interior se elaboró con una aleación de plata, oro y cobre (Tab. 2, PA11823 a-c), mientras que el resto de los elementos que lo integran presentan una naturaleza áurea. Se observan además algunas diferencias significativas de composición entre dichos elementos, por ejemplo, la existente en la proporción de plata y cobre entre el tubo con decoración geométrica de la zona central respecto a la placa con espirales y los restos de alambres enrollados del lateral (Tab. 2, PA11823 d-f).

El terminal del torques (Inv. 33.137) presenta también diferencias de composición entre sus elementos, con una menor proporción de plata en su disco frontal decorado respecto al cuerpo central analizado (Tab. 2, PA 11824 a-b). Los restos de alambres enrollados que incorpora en su parte posterior, ofrecen a su vez diferencias significativas en la plata respecto a los presentes en el fragmento 33.133, perteneciendo probablemente al recubrimiento del lateral no conservado del aro (Tab. 2, PA11824 c).

La diversidad de composiciones observada en la pieza de Cangas de Onís nos señala otra realidad también presente en el resto de los torques estudiados, y es la diferente composición de los elementos que los integran. Esta particularidad se ha observado no sólo en elementos de carácter ornamental, como pueden ser placas decoradas, tramos de alambres enrollados o cuerpos de filigrana, sino también entre los elementos que forman la estructura básica del torques: terminales y aros. Las diferencias de composición señalan hacia una manufactura de dichos elementos por separado, siendo el procedimiento de unión más empleado la soldadura (Armbruster y Perea, 2000; Monge et al. 2004: 135), aunque en algunos casos ésta no se aprecie con nitidez. En la Est. V, Fig. 1 se han representado dos casos claros de esta diversidad (inventarios 1972/113/1 y 1972/64/4) donde no solo varía el porcentaje de plata, sino también las cantidades de cobre utilizadas en las aleaciones. Una excepción dentro de esta muestra la constituye el torques o brazalete 1972/113/2, que probablemente fue fundido en una sola pieza.

-133). Este tratamiento facilitó la posibilidad de realizar un análisis más adecuado de los elementos que integra el ejemplar, del que pudimos analizar el fragmento de aro 33.133 y el terminal 33.137.

Conimbriga, 46 (2007) 89-115 
El estudio analítico de los objetos que forman parte de los restantes lotes de materiales aporta también otros datos de interés que vienen a completar los obtenidos en su revisión topográfica.

Los torques del lote de Madorra ofrecen una relativa diversidad formal, incluyendo algún ejemplar muy poco frecuente en el ámbito castreño (1972/64/5), aunque también tipos mejor documentados, con piezas muy semejantes entre sí.

Podemos diferenciar, por un lado, los torques 1972/64/1, 1972/ /64/2 y 1972/64/3, piezas que incorporan tramos de alambres enrollados en los laterales del aro y decoración de filigrana en su zona central, variando tanto en sus dimensiones como en la morfología de los tramos de alambres enrollados y terminales. Dentro de este grupo, los ejemplares núms. 1972/64/2 y 1972/64/3 mantienen sin duda una evidente relación tipológica, observándose notables semejanzas en su manufactura y técnicas de fabricación, aspectos que podrían señalar su pertenencia un mismo taller de fabricación. El estudio analítico de estas dos piezas no descarta esta hipótesis, pues tanto la composición de los tramos de alambres enrollados como la de los cuerpos ornamentales de filigrana son muy semejantes, variando sin embargo la composición de sus terminales (Tab. 2, PA11692 a-b y PA11684 a); lo mismo puede señalarse respecto a las composiciones del ejemplar 1972/64/1 en relación con los anteriores.

Podemos observar también una cierta similitud formal y tecnológica entre los terminales de las piezas 1972/64/1 y 1972/64/4 de este lote, sin embargo, en este caso las composiciones de estos elementos son muy diferentes, e incluso varían significativamente dentro del ejemplar 4 (Tab. 2, PA11693 a-b), donde se ha observado un fallo en la zona de soldadura de uno de los terminales, quizá fruto de una manipulación sufrida por el ejemplar.

Finalmente, el torques de A Madorra 1972/64/5, muy próximo formalmente a otro ejemplar de plata procedente de Mondoñedo (López Cuevillas, 1951; Balseiro, 1999-2000) supone, al igual que éste, un caso atípico entre los torques recuperados en este ámbito, presentando una tipología de clara influencia meseteña, aunque contrastando sin embargo con las producciones de estas regiones, donde las piezas se manufacturaban principalmente en plata. Su estructura integra un aro de desarrollo funicular con adornos de lazos en su parte central, conseguido a partir del trabajo con tramos de alambre de sección cóncavo-convexa e hilos de menor diámetro, de sección circular, que recubren 
totalmente un vástago o alma interior no analizado (García Vuelta, e.p.); los adornos de lazos se consiguieron probablemente a partir del martillado y la deformación plástica de los mismos tramos con los que se recubrió el alma interior de la pieza. Los cuerpos macizos que forman los extremos del ejemplar, que incluyen terminales vueltos al exterior muy similares a los de la pieza 1972/113/2, fueron probablemente fundidos y soldados posteriormente a ambos lados del cuerpo funicular. Los análisis realizados sobre este ejemplar indican una composición diferenciada entre estos elementos y la parte central del aro, donde aparecen cantidades de cobre $(0,3 \%)$, apreciándose en los extremos un mayor porcentaje de plata y ausencia de cobre (Tab. 2, PA 11674 a-b).

Un aspecto debatido sobre esta pieza es su adscripción cultural. En función de su tipología y materiales de fabricación, el torques de plata de Mondoñedo se ha descrito como una producción de origen celtibérico ajena al ámbito castreño (Raddatz, 1969; Balseiro, 1999-2000). Por su parte, el torques 1972/64/5 ha sido estudiado como una reinterpretación indígena de modelos de origen celtibérico (Ladra, 1997-1998: 57), opción que parece más probable, a tenor de la tecnología y los materiales de fabricación del ejemplar. En este sentido, y aunque los datos analíticos no pueden considerarse concluyentes, hay que observar que la composición de esta pieza sigue los mismos patrones que la mayoría de los torques de oro analizados, coincidiendo además con la de otras producciones de este ámbito.

De forma inversa, otro ejemplo atípico lo constituye también el torques de plata 1974/64/6 de Sobrado dos Monxes. En este caso, se trata de una pieza de tipología netamente castreña, a diferencia de otros ejemplos conocidos fabricados en este metal, como los de Cortinhas o Bagunte, que responden a formas más propias de otros ámbitos peninsulares (López Cuevillas, 1951). Los análisis de este torques (Tab. 2, PA11685 a-b) han confirmado la composición argéntea de la pieza, y no han permitido documentar en su superficie vestigios claros de elementos áureos o del uso de técnicas destinadas a un recubrimiento de la pieza con este metal, como el dorado o el chapado.

Al igual que se ha observado en el lote de Madorra, las composiciones de las piezas de oro del expediente 1972/113 ofrecen también una notable diversidad compositiva, tanto entre los elementos estructurales que conforman los objetos (Est. V, Fig. 2) como entre éstos, sin 
que puedan establecerse a partir de este estudio hipótesis fiables sobre posibles relaciones de hallazgo entre las piezas.

Buenos ejemplos de esta diversidad lo constituyen el torques 1972/113/1 (Est. II, 1) y el torques o brazalete 1972/113/4, ejemplar en el que se aprecian diferencias próximas a un $3 \%$ en la composición de oro y plata de sus terminales, y de hasta un 5\% entre terminales y aro, sin que se haya detectado presencia de cobre (Tab. 2, PA11687 a-c). La misma línea siguen las piezas 1972/113/6 y 1972/113/5.

Una excepción es el torques o brazalete 1972/113/2, que como el ejemplar 1972/64/5 presenta una tipología poco frecuente en el ámbito castreño. Esta pieza ha sido objeto de varios análisis para determinar posibles diferencias de composición entre el aro y los terminales, al no haberse identificado restos claros de soldadura en el estudio topográfico. Los resultados son sin embargo ambiguos, ya que la composición, aunque no estrictamente similar, no es lo suficientemente diferente, por lo que no han podido demostrarse definitivamente hipótesis como la de su fabricación a la cera perdida. Ambos incluyen un porcentaje medio de cobre $(0,7-0,9 \%)$ en sus aleaciones, y la diferencia en la composición de la plata es apenas de $1,5 \%{ }^{8}$.

\section{Comparación de análisis}

La comparación de los datos obtenidos en esta muestra con los análisis de Hartmann es compleja, ya que muchos de los ejemplares ahora analizados no se adaptan de una forma exacta a las características de los principales grupos de composición establecidos por el autor alemán para las piezas de este ámbito.

Un problema añadido se presenta en la valoración del estaño, al tener el equipo empleado en nuestro estudio un límite de detección elevado, en algunos casos en torno al $0,3-0,2 \%$, por lo que su presencia en cantidades inferiores, como es habitual en los análisis de Hartmann, no es posible confirmarla. La presencia del estaño se ha valorado en la

8 Esta pequeña variación podría deberse a la propia incertidumbre en la cuantificación de los análisis, que incluye el margen de error analítico y las diferentes condiciones de análisis causadas por una geometría diferente en las piezas (superficie curva frente a superficie romboidal). 
definición de dichos grupos, y su importancia también se ha destacado a la hora de señalar la procedencia aluvial de los oros castreños (Pérez Outeiriño, 1989; Montero y Rovira, 1991).

Otros inconvenientes, en este caso derivados de la metodología de trabajo empleada por el investigador alemán son, por un lado, el desconocimiento en la mayor parte de sus análisis de cual fue la zona muestreada de las piezas, y por otro, el hecho de contar en la mayoría de las ocasiones con un único análisis por objeto. Todos estos aspectos dificultan aún más la confrontación de la información, pues en el presente estudio se ha destacado la valoración del análisis de los distintos elementos estructurales y ornamentales documentables en los objetos.

El análisis de la pieza del lote de Cangas de Onís, que sí fue analizada previamente por Hartmann, supone un buen ejemplo de estos problemas de comparación, y también del establecimiento de grupos cerrados en los oros del ámbito castreño. En los tres análisis realizados, uno para cada fragmento (Hartmann, 1982: SAM 1846, 1843 y 1844), Hartmann incluyó dentro de su grupo TC el aro 33.133, que ofrece trazas de $\mathrm{Sn}$, y el terminal 33.137, que no las presenta, superando en ambos casos los límites del $20 \%$ en sus composiciones de Ag y Cu (SAM 1844 y 1843) ${ }^{9}$. Sin embargo, el investigador diferenció la composición del terminal 33.138, con composiciones más bajas de $\mathrm{Ag} \mathrm{y} \mathrm{Cu}$, incluyéndolo en un amplio conjunto de "Resto de Grupos" (SAM 1846).

9 El grupo TC de Hartmann se caracteriza por sus altos contenidos de $\mathrm{Ag} \mathrm{y} \mathrm{Cu}$, con porcentajes entre un 20 y un $50 \%$ Ag y entre el 15 y el $50 \% \mathrm{Cu}$. Pueden incluir además una cantidad variable de Sn, interpretable como impureza del oro aluvial, o como resto de posibles ligas anteriormente realizadas con el cobre. La presencia de otros elementos secundarios también se ha entendido como producto de ligas previas o de fundiciones previas realizadas con el mismo crisol (Hartmann, 1982). Dentro del grupo TC se incluyen, entre otras, piezas como otro de los torques del lote de Cangas de Onís (n. ${ }^{\circ}$ 33.132), un torques de la provincia de Lugo en el M.A.N., los de Sta. María de Foxados en el Museo de Pontevedra, o terminales de Lebução y Estela. 
TABLA 3 - Comparación de los resultados analíticos obtenidos por Hartmann (SAM) y los presentados en este trabajo (PA)

\begin{tabular}{|c|c|c|c|c|c|c|c|c|c|}
\hline Inventario & & ANÁLISIS P & & & & & ANÁL & IS SAM & \\
\hline \multirow{7}{*}{33.133} & Muestra & Elemento / Zona & $\mathbf{A u}$ & $\overline{A g}$ & $\mathbf{C u}$ & Muestra & $\mathbf{A g}$ & $\mathrm{Cu}$ & Sn \\
\hline & PA11823e & Aro-Placa espirales & 68,35 & 30,4 & 1,2 & \multirow{6}{*}{1844} & \multirow{6}{*}{$>23$} & \multirow{6}{*}{ c.a. 26} & \multirow{6}{*}{0,61} \\
\hline & PA11823d & Aro-Tubo central & 53,56 & 41,3 & 5,2 & & & & \\
\hline & PA11823b & Aro-Barra interior & 38,02 & 44,9 & 17,0 & & & & \\
\hline & PA11823c & Aro-Barra interior & 37,14 & 46,5 & 16,4 & & & & \\
\hline & $\begin{array}{l}\text { PA11823a } \\
\end{array}$ & Aro-Barra interior & 29,38 & 57,5 & 13,2 & & & & \\
\hline & PA11823f & Aro-Alambre enrollado & 65,35 & 32,6 & 2,1 & & & & \\
\hline \multirow{3}{*}{33.137} & $\begin{array}{l}\text { PA11824b } \\
\end{array}$ & $\begin{array}{c}\text { Terminal-Cuerpo } \\
\text { intermedio (frontal) }\end{array}$ & 64,64 & 34,7 & 0,6 & \multirow{3}{*}{1843} & \multirow{3}{*}{$\begin{array}{l}\text { c.a. } \\
35\end{array}$} & \multirow{3}{*}{ c.a. 21} & \multirow{3}{*}{ n.d } \\
\hline & PA11824a & Terminal-Disco frontal & 73,56 & 26,2 & 0,2 & & & & \\
\hline & PA11824c & $\begin{array}{c}\text { Terminal-Alambre } \\
\text { enrollado }\end{array}$ & 55,92 & 41,5 & 2,5 & & & & \\
\hline 33.138 & -- & -- & -- & -- & -- & 1846 & $>20$ & 2,2 & 0,025 \\
\hline
\end{tabular}

Como se observa en la tabla 3 , nuestros resultados en el aro 33.133 varían significativamente respecto a las cantidades de $\mathrm{Cu}$ documentadas por Hartmann, no alcanzándose en ningún análisis el 20\%, aunque superando algunos el 15\%, correspondiendo éstos a su vástago interior. Los porcentajes de $\mathrm{Ag}$ y $\mathrm{Cu}$ en este elemento permitirían incluirlo dentro del grupo TC de Hartmann, sin embargo, es la plata el elemento mayoritario de composición. El resto de los elementos del aro no alcanzan las proporciones de $\mathrm{Cu}$ estimadas por el autor alemán para su caracterización dentro del grupo TC. Aunque alguno de estos resultados podrían incluirse con reservas en el "resto de grupos" (B?) de Hartmann. La falta de resolución en la cuantificación de los elementos traza impide establecer una relación fiable con las piezas de este grupo (Hartmann, 1982). Respecto al terminal 33.137 también se observan diferencias muy significativas, variando así mismo a la baja los porcentajes de $\mathrm{Cu}$.

Estos resultados, sin embargo, deben observarse en un nivel comparativo más general. Como recientemente ha señalado Warner (2004), en el reanálisis de los materiales irlandeses, los valores de $\mathrm{Cu}$ y $\mathrm{Sn}$ suelen ser concordantes con los ofrecidos por Hartmann, no así los de Ag, que suelen ser más bajos en los análisis del Proyecto SAM. Por tanto, la valoración de altos contenidos de $\mathrm{Ag}$ y $\mathrm{Cu}$ sería coincidente aunque los valores concretos no ajusten con precisión, entre otras razones, por la propia variabilidad de las piezas, sin que podamos determinar la zona exacta analizada por Hartmann o cómo fue extraída la muestra. En segundo lugar, porque los oros con alto contenido en $\mathrm{Cu}$ tienden a pre- 
sentar heterogeneidades en superficie (Guerra y Calligaro, 2004: 1204). En cualquier caso, no hay que olvidar que el autor alemán ofrece valores orientativos cuando los porcentajes presentes son elevados, y que la plata se midió o bien por gravedad específica o por vía húmeda, métodos de menor precisión que el OES utilizado para los elementos traza.

\section{Conclusiones}

Este estudio ha ampliado significativamente el repertorio de información disponible sobre la colección de orfebrería castreña del MAN, y ha permitido apuntar también algunas consideraciones metodológicas de interés.

Como se ha señalado, la mayor parte de la información disponible sobre los oros castreños fue conseguida analizando muestras extraídas de un punto concreto de los objetos, que en la mayoría de los casos no se especificó (Hartmann, 1982). La información obtenida en esta nueva caracterización de piezas del MAN señala sin embargo la conveniencia de identificar y valorar los elementos estructurales y ornamentales de los materiales a partir de un estudio topográfico previo. Dichos elementos deben ser considerados a la hora de obtener - y sobre todo de interpretar - los resultados analíticos, pues como se ha observado en el ejemplo de Cangas de Onís, su exclusión puede repercutir significativamente en las conclusiones obtenidas.

Sin embargo, los resultados indican también que la información obtenida con esta metodología, que pone de manifiesto la complejidad de la caracterización de estos materiales debe ser igualmente manejada con prudencia a la hora de la interpretación. Dejando al margen las conclusiones relativas al estudio individual de cada objeto, la muestra analizada ha permitido observar unas composiciones diferenciadas entre los elementos integrantes de las piezas. Estas diferencias parecen apuntar hacia un proceso de manufactura concebido en diferentes pasos o coladas, sin que necesariamente el tiempo transcurrido entre ellas sea largo, y sin que las variaciones observadas sean tan grandes como para pensar en aspectos como efectos cromáticos intencionados.

A la hora de interpretar las composiciones obtenidas, hay que tener en cuenta la composición del oro aluvial. Este oro contiene proporciones variables de plata que podrían justificar de manera natural los porcentajes detectados en los torques sin necesidad de pensar en aleaciones 
o manipulaciones del oro ${ }^{10}$. Por otro lado, la presencia o ausencia de pequeños porcentajes de cobre está también generalmente vinculada al propio oro aluvial. Solamente en aquellos casos en los que el porcentaje de este elemento supera el $1 \%$ tenemos cierta seguridad de encontrarnos ante una aleación intencional (Montero y Rovira, 1991). Según este principio, la serie estudiada podría estar compuesta mayoritariamente por oros no aleados, y por lo tanto, la variabilidad compositiva detectada en los elementos podría obedecer en ciertos casos a la variabilidad natural del oro procesado, sin necesidad de explicaciones alternativas.

Sin embargo, esta hipótesis solo podrá ser corroborada a través de exhaustivos análisis de composición obtenidos en las distintas zonas auríferas de estas regiones que confirmen cual es la composición original de ese oro. Además, no podemos descartar que se produzca una voluntad de alterar la composición original del oro por parte de los orfebres, bien mediante la adición de pequeñas cantidades de plata, o por mezclas de oro reciclado que incorporan a su vez pequeñas cantidades de cobre, pues algunos análisis son inequívocos de esta práctica ${ }^{11}$.

En cualquier caso, lo que si parece probable es que en la manufactura de estos torques no se partía de una materia prima en un único lingote, pues una fragmentación del lingote para una fundición - ya sea única o por separado - de los elementos que forman la pieza daría como resultado una composición similar en todos ellos. Este dato, apunta pues a favor de la metodología de muestreo propuesta en este estudio, al ofrecer una idea más aproximada de las técnicas y materias primas documentables en los objetos.

Las cuestiones abiertas evidencian el largo camino que aún queda por recorrer para lograr una adecuada caracterización de los modos de producción y las técnicas de fabricación utilizados en la orfebrería castreña. En este sentido, es importante señalar que a pesar del lento aun-

10 El electrum natural puede alcanzar porcentajes de plata de hasta un $40 \%$. La composición de las pepitas de oro no es homogénea, por lo que la composición final de los oros aluviales será en cierta medida diferente unos de otros, ya que son el resultado de la suma de cada una de las pepitas individuales. Las diferencias de composición pueden acentuarse además si el oro procede de distintas zonas de un mismo río aurífero. Una vez fundido un volumen determinado de metal, este se homogeniza en su composición global.

11 Solo el torques de Cangas de Onís, y algunos elementos de las piezas integradas en el expediente 1972/113 del MAN son oros claramente aleados. 
que progresivo aumento en el número de datos topográficos y analíticos disponibles, no contamos todavía con un corpus de información exhaustivo y adecuadamente publicado para el estudio de todos los materiales conocidos. Hay que tener también en cuenta que la adecuada determinación de las procedencias de los oros, otro de los temas importantes pendientes de revisión, solo puede abordarse con técnicas analíticas más precisas y para áreas geográficas amplias, como se ha indicado recientemente (Guerra y Calligaro, 2004).

Estos factores, junto a otros, siguen dificultando el establecimiento de grupos definitivos de clasificación en las aleaciones castreñas y mantienen abiertas diversas e importantes cuestiones sobre la tecnología de este ámbito. Entre estos aspectos, podemos destacar el estudio de los procedimientos de unión empleados por los orfebres castreños a lo largo del tiempo (Monge et al., 2004), o la adecuada caracterización de prácticas cada vez mejor documentadas en estas regiones, como el chapado, que sin duda contribuirán a una lectura general más adecuada de la orfebrería castreña.

A la espera de estos datos, los estudios analíticos, lejos de ser interpretados como un fin en si mismo, deben generalizarse como una parte importante en el proceso general de investigación de los materiales. Este trabajo, integrado en un estudio de conjunto de los objetos de la colección del MAN (García Vuelta, e.p.), ha supuesto un intento en ese sentido.

\section{BIBLIOGRAFÍA}

Acuña Castroviejo, F.; Casal García, R. (1984-1985) - "Un novo torques de aramios enrolados". Brigantium 5: 261-269.

Almagro-Gorbea, M.; Casado, D.; Fontes, F.; Mederos, A.; Torres, M. (2004) - Real Academia de la Historia. Catálogo del Gabinete de Antigüedades. Prehistoria. Antigüedades Españolas I. Madrid.

ÁlvareZ-Ossorio, F. (1954) - "Tesoros españoles antiguos en el Museo Arqueológico Nacional". Boletín de la Real Academia de la Historia CXXXV, cuaderno II: 257-323.

- (1931) - Museo Arqueológico Nacional. Adquisiciones en 1931: Joyas de oro,

Post-Hallstáticas, procedentes de Cangas de Onís. (Oviedo). Blas S. A. Tipográfica. Madrid.

Alves, L. C.; AraúJo, M. F.; Soares, A. M. M. (2002) - "Estudo de um torques proveniente do noroeste peninsular - aplicação de métodos instrumentais de análise química não destrutivos". O Arqueólogo Português 20. Série IV: 115-134

Armbruster, B. R. (2000) - Goldschmiedekunst und Bronzetechnik. Studien zum 
Metallhandwerk der Atlantischen Bronzezeit auf der Iberischen Halbinsel. Monographies Instrumentum 15. Montagnac.

- (1998) - "Quelques aspects technologiques de l'orfèvrerie du Bronze Final au début de l'Âge du Fer, au Portugal et en Galice". En Nicolini, G. y Dieudonné-Glad, N. (Eds.): Les metaux antiques: travail et conservation. Monographies Instrumentum 6. Montagnac: 53-58.

Armbruster, B. R.; Perea, A. (2001) - "Goldschmiedearbeiten der eisenzeitlichen Castro-Kultur I/II". En Ulbert, T. (Ed.) y Koch, M (Coord): Hispania Antiqua. Deutsches Archäologisches Institut, Madrid. Mainz: 389-398.

- (2000) - "Macizo/hueco, soldado/fundido, morfología/tecnología. El ámbito tecnológico castreño a través de los torques con remates en doble escocia". Trabajos de Prehistoria 57 (1): 97-114.

BALSEIRo GarCíA, A. (1999-2000) - "El torques argénteo de Mondoñedo: un producto foráneo". Boletín do Museo Provincial de Lugo IX: 17-25.

Barril Vicente, M.; Rodero RiazA, A. (Coord.) (2002) - Torques, Belleza y poder. Ministerio de Cultura. Madrid.

Blanco Freijeiro, A. (1957) - "Orígenes y relaciones de la orfebrería castreña". Cuadernos de Estudios Gallegos XII: 5-28; 137-157; 267-301.

BouZA-Brey, F. (1965) - "Tres torques áureos de Galicia". Cuadernos de Estudios Gallegos 20. Fasc. 60: 5-11.

Calo Lourido, F.; Soeiro, T. (1986) - Castro de Baroña. Campañas 1980/84. Arqueología/Memorias 6. Xunta de Galicia. Santiago de Compostela.

EluÈre, Ch. (1986-1987) - "Enigmatiques images d'hommes dans l'orfèvrerie de l'Âge du Fer". Antiquités Nationales 18-19: 193-203.

FernáNDEZ-Posse, M. D. (1998) - La investigación protohistórica en la Meseta y Galicia. Madrid.

García Vuelta, O. (en prensa) - Orfebrería Castreña en el Museo Arqueológico Nacional. Ministerio de Cultura. Madrid.

- (2003) - "Aspectos morfotécnicos de las diademas-cinturón castreñas". Brigantium 14: 151-172.

- (2001) - "El conjunto de Cangas de Onís: arqueología del oro castreño asturiano". Trabajos de Prehistoria 58 (2): 109-127.

- (2000) - "La colección de orfebrería castreña del Museo Arqueológico Nacional. Notas para el estudio de su evolución". Boletín del Museo Arqueológico Nacional XVIII: 69-96.

García Vuelta, O.; Perea, A. (2001) - "Las diademas-cinturón castreñas: el conjunto con decoración figurada de Moñes (Villamayor, Piloña, Asturias)". Archivo Español de Arqueología 74: 3-23.

Guerra, M. F.; Calligaro, T. (2004) - "Gold traces to trace the Gold". Journal of Archaeological Science 31: 1199-1208.

Hartmann, A. (1982) - Prähistorische Goldfunde aus Europa II. Spektranalytische Undersuchungen und deren Auswertung. Studien zu de Anfängen der Metallurgie. Band 5. Berlín.

- (1971) - "Análises de alguns objectos pré-históricos de ouro, procedentes do Norte de Portugal". Revista de Guimarães LXXXI (1 y 2): 129-133. 
LAdRA FERnÁndeZ, X. L. (1997-1998) - “Ouros no desterro: notas encol de dous conxuntos inéditos de ourivesaria castrexa actualmente depositados no M.A.N." Boletín do Museo Provincial de Lugo VIII (1): 45-78.

- (1996) - "Torques de A Madorra 1; 2; 3; 4; 5; Torques de Sobrado dos Monxes". Fichas de Catálogo en VV.AA: El oro y la orfebrería prehistórica de Galicia. Lugo: 117; 119; 121; 122.

López Cuevillas, F. (1951) - Las joyas castreñas. Madrid.

MAya GonzÁlez, J. L., 1987-1988 - La cultura material de los castros asturianos. Estudios de la Antigüedad 4-5. Bellaterra.

Monge Soares, A. M.; Fátima Araújo, M. de; Cerqueira Alves, L. (2004) - “Análise química não-destrutiva de artefactos em ouro pré e proto-históricos: alguns exemplos". Revista Portuguesa de Arqueologia 7 (2): 125-138.

Monteagudo García, L. (1952) - "Torques castreños de alambres enrollados". Archivo Español de Arqueología 25: 287-296.

Montero, I.; RovirA, S. (1991) - "El oro y sus aleaciones en la orfebrería prerromana". Archivo Español de Arqueología 64: 7-21.

Moreno Cifuentes, M. A.; DÁvila Buitrón, C. (2002) - "Conservación de los torques del Museo Arqueológico Nacional”. En Barril, M. y Rodero, A. (Dir.): Torques, Belleza y Poder. Madrid: 129-157.

Nicolini, G. (1990) - Tecniques des ors antiques. La bijouterie ibérique du VIIe au IVe siècle. París.

PEÑA SAnTos, A. de la. (1996) - "La secuencia cultural del mundo castrexo galaico". En Hidalgo Cuñarro, J. M. (Coord.): A Cultura castrexa galega a debate. Tui: 65-103.

PereA, A. (2003) - "Los torques castreños en perspectiva. Brigantium 14: 139-149. - (1991) - Orfebrería Prerromana. Arqueología del oro. Madrid.

Perea, A.; Adeva, P.; Aballe, M. (1991) - "SEM-EDS microanalytical study of preroman gold objects from the Iberian Peninsula". En Waldren, W. H.; Ensenyat, J. A.; Kennard, R. C. (Eds.): II Deia Conference of Prehistory. British Archaeological Reports. International Series 573: 239-266.

Perea, A.; Alguacil, F. J.; Adeva, P.; García Vuelta, O. (2003) - "Contaminación y conservación de piezas de orfebrería prehistórica. ¿Es el oro un metal sin tiempo?". Revista de Metalurgia 39 (1): 3-8.

PÉREZ OuteIRIÑO, B. (1992) - "Almacenamento de materias primas entre os ourives castrexos: lingotes planoconvexos”. En Acuña, F. (Coord.): Finis Terrae. Estudos en lembranza do Prof. Alberto Balil. Santiago de Compostela: 97-130.

- (1990) - “Achega tipolóxica para o estudio dos torques áureos do NW”. Gallaecia 12: 139-151.

- (1989) - “Orfebrería castreña”. En VV.AA. El oro en la España Prerromana. Revista de Arqueología. Madrid: 90-107.

- (1982) - De Ourivesaria castrexa. Arracadas. Boletín Auriense. Anexo I. Orense.

PIngel, V. (1992) - Die Vorgeschichtlichen Goldfunde der Iberischen Halbinsel. Eine Archäologische Untersuchung zur Auswertung der spektralanalysen. Madrider Forschungen. Band 17. Berlín-New York.

Prieto Molina, S. (1996) - "Los torques castreños del Noroeste de la Península Ibérica”. Complutum 7: 195-223. 
RadDATZ, K. (1969) - Die Schatzfunde der Iberischen Halbinsel. Berlín.

SÁnCHEZ-PALENCIA, F. J. (1997) - "La tierra que florece de plata, estaño y oro blanco. Notas sobre la minería antigua en el territorio de los Ártabros". En Alonso Troncoso, V. (Ed): Ferrolterra Galaico-Romana. Ferrol: 41-47.

- (1996) - “Arqueominería del oro: el Noroeste peninsular". En Calvo, B.; Bernárdez, M. J.; Guisado, J. C (Coords.): Arqueología e historia de la minería y la metalurgia. Madrid: 87-106

SÁnchez-PAlencia, F. J.; FernándeZ-Posse, M. D. (1998) - "El beneficio del oro por las comunidades prerromanas del Noroeste peninsular". En Delibes de Castro, G. (Coord.): Minerales y metales en la Prehistoria Reciente. Algunos testimonios de su explotación y laboreo en la antigüedad. Studia Archaeologica 88. Valladolid: 227-246.

Silva, A. C. Ferreira da (1986) - A Cultura Castreja no Noroeste de Portugal. Paços de Ferreira.

Somoano, C. (1960) - "La colección "Soto Cortés" de Labra". Boletín del Instituto de Estudios Asturianos 40: 269-291.

VÁzquez VARela, J. M. (1995) - "Etnoarqueología de la extracción del oro de los ríos en el Noroeste de la Península Ibérica”. Trabajos de Prehistoria 55 (2): 157-161.

Villa Valdés, A. (2004) - "Orfebrería y testimonios metalúrgicos en el castro de Chao Sanmartín (Asturias, España): estudio cronoestratigráfico (Siglos IV a. C.-II d. C.)”. En Perea, A.; Montero, I.; García Vuelta, O. (Eds.): Tecnología del oro antiguo: Europa y América. Anejos de Archivo Español de Arqueología XXXII. Madrid: 253-264.

WARNER, R. (2004) - "Irish gold artefacts: observations from Hartmann's analytical data". In Roche, H. et al. (Eds): From Megaliths to Metal. Essays in Honour of George Eogan. Oxford. 
EST. I
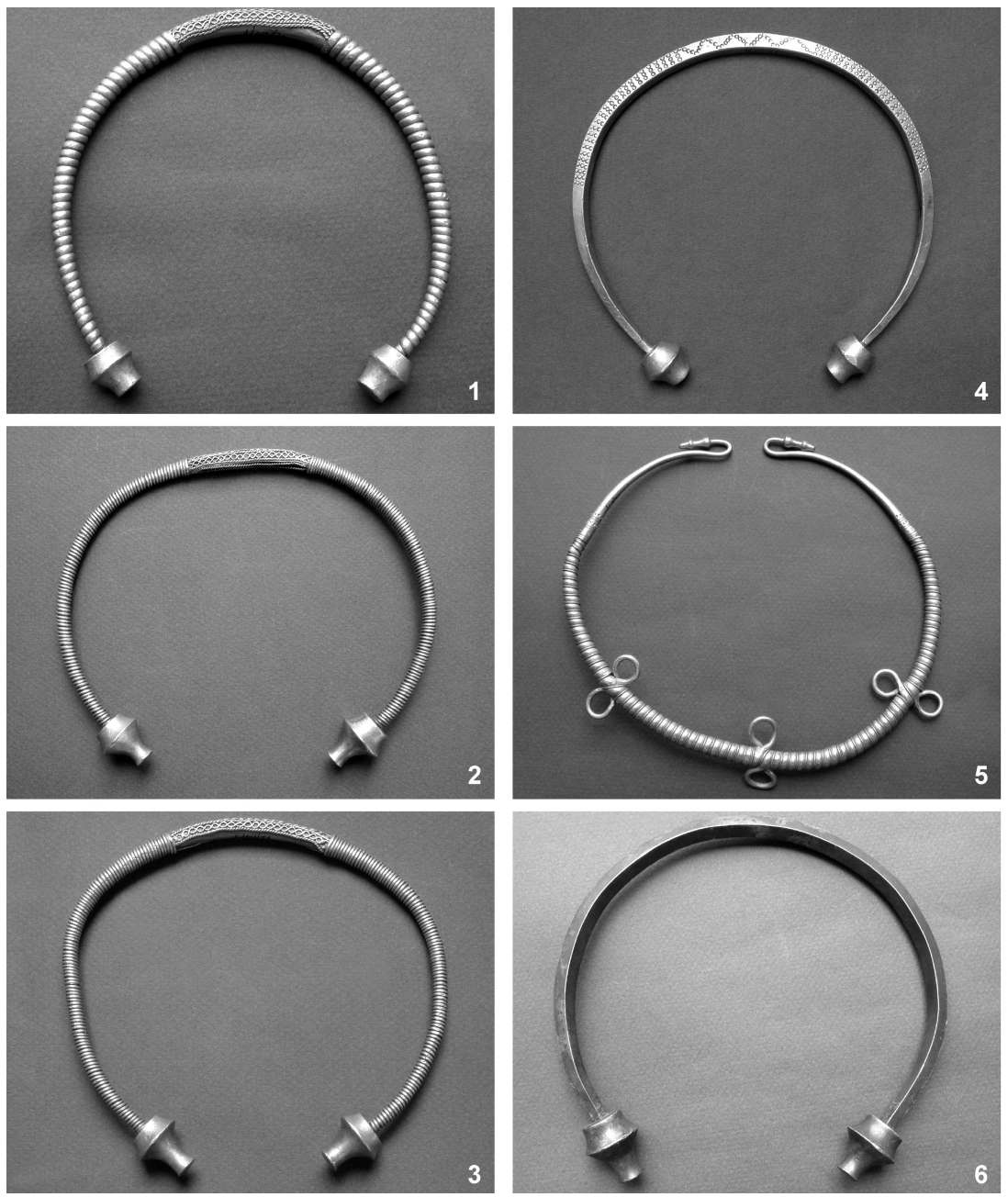

Torques del expediente 1972/64 del M.A.N. 1 a 5: Torques de oro de A Madorra. Inventarios 1972/64/1-5; 6. Torques de plata de Sobrado dos Monxes (Inventario 1972/64/6). Fotos O.G.V. 
EsT. II
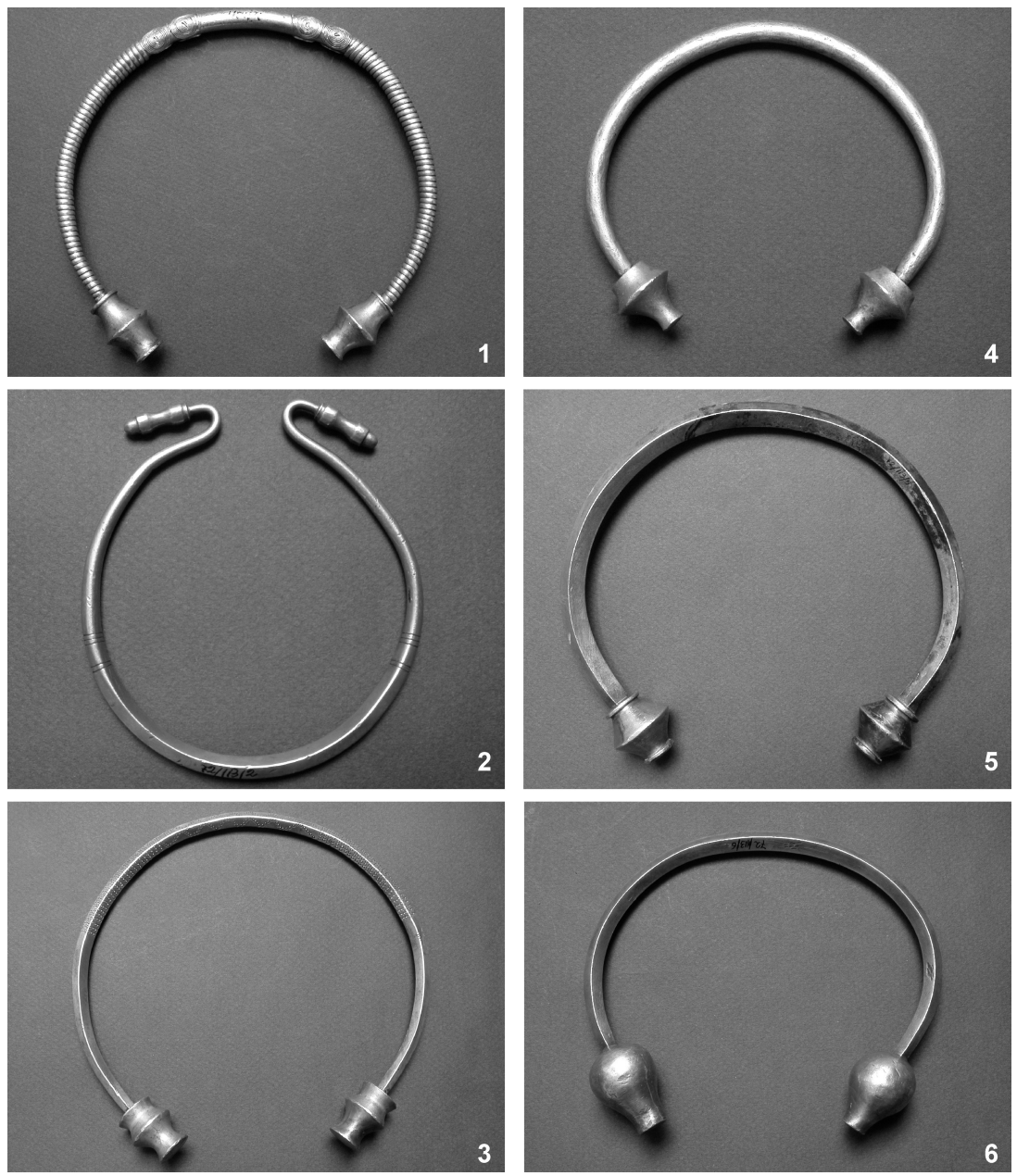

Torques de oro del expediente 1972/113 del M.A.N. Inventarios 1972/113/1-6. Procedencia incierta. Fotos O.G.V. 
EsT. III

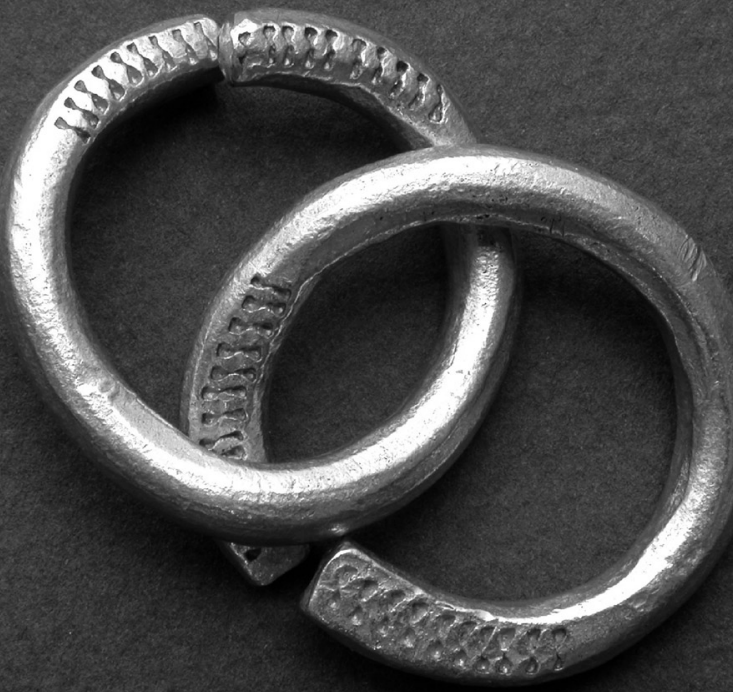

FIG. 1 - Pareja de anillas abiertas entrelazadas con extremos estampados, adquiridas junto a los torques del expediente 1972/113. Procedencia Incierta. Fotos O.G.V.

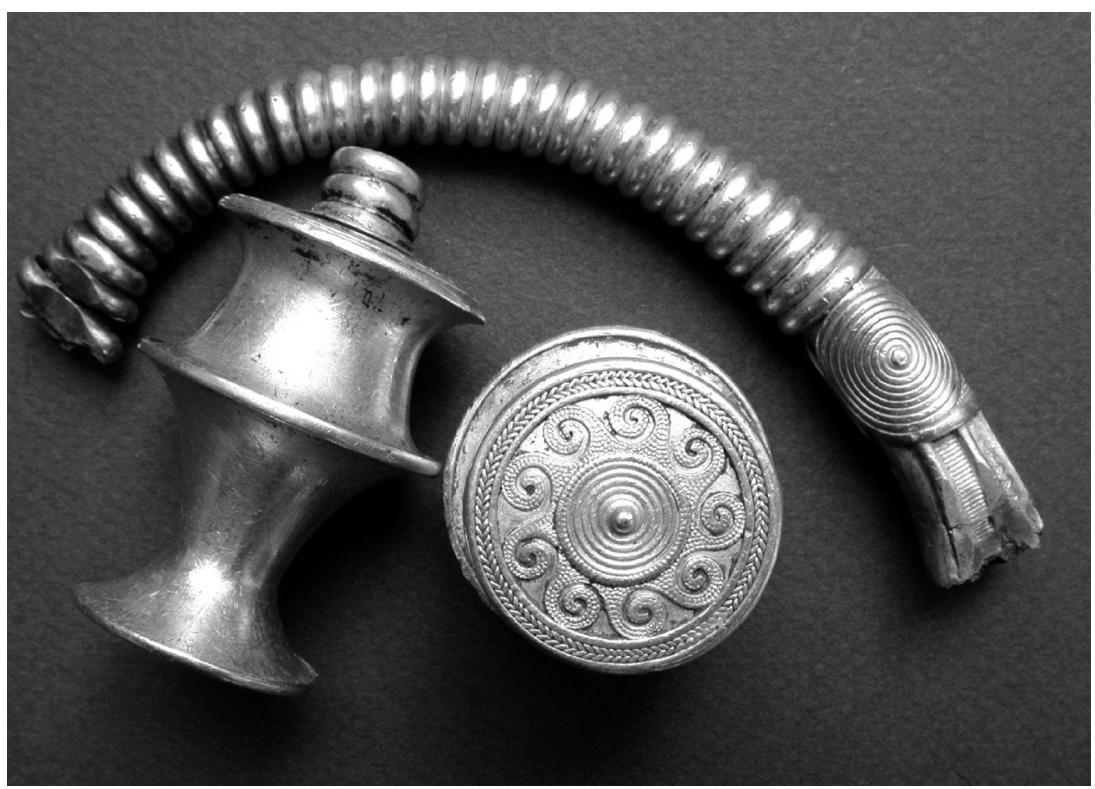

FIG. 2 - Fragmentos de torques con procedencia supuesta de Cangas de Onís (Asturias). Inventario: 33. 133, 33. 137 y 33. 138. Fotos O.G.V. 
Est. IV

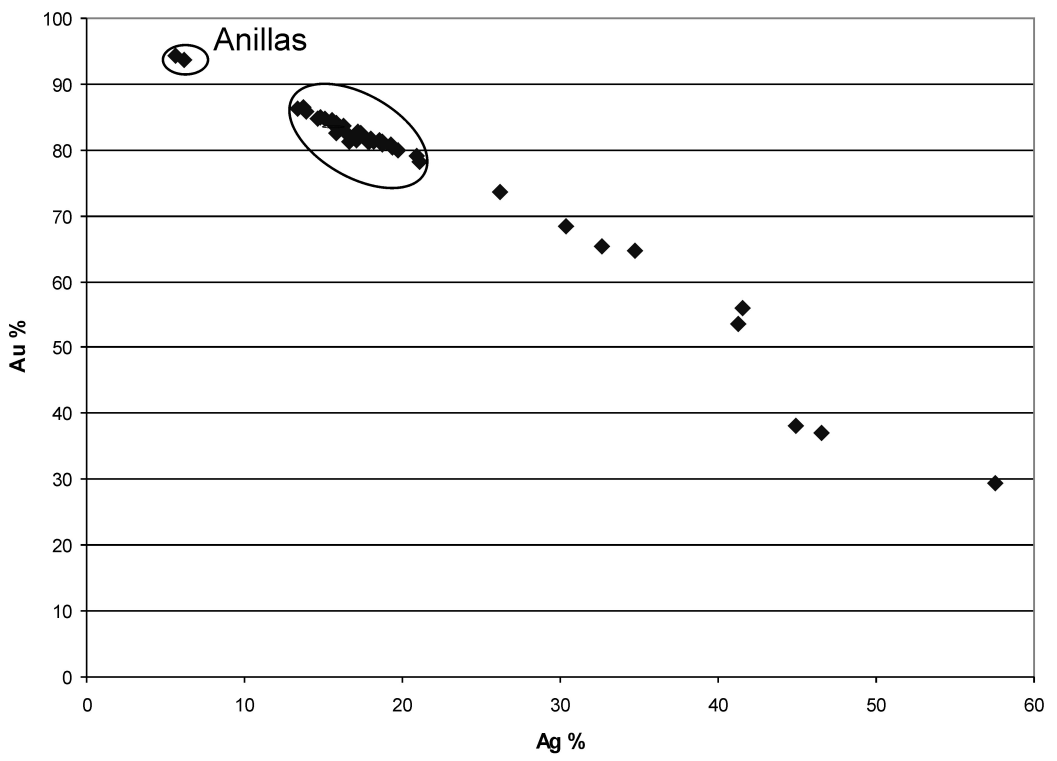

FIG. 1 - Distribución de los grupos de composición de todos los elementos de oro analizados.

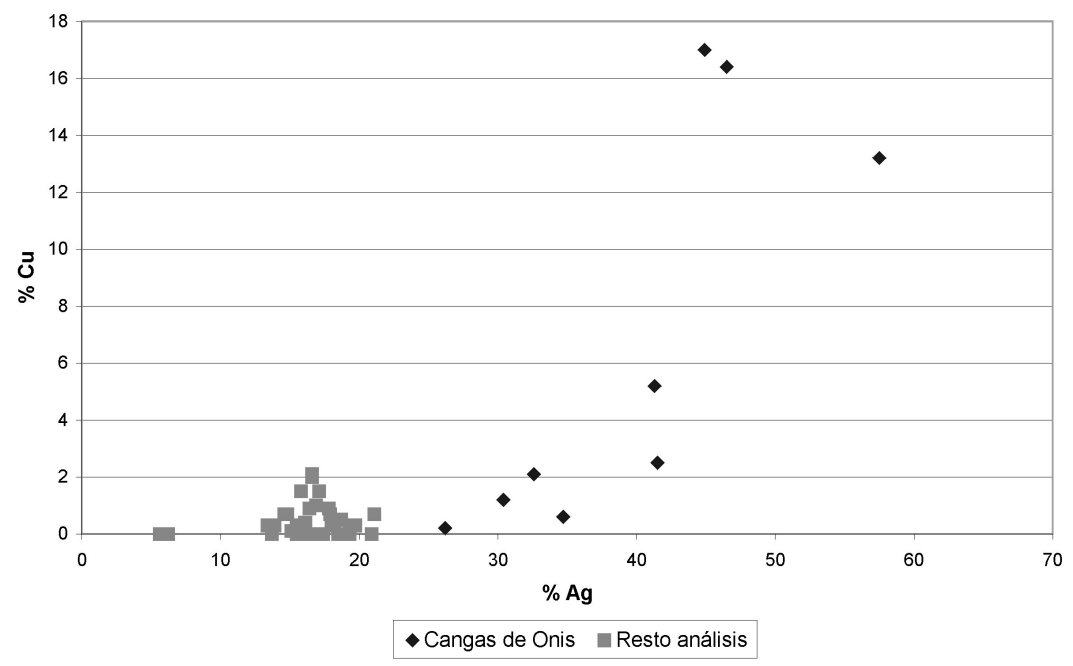

FIG. 2 - Comparación de los resulatados obtenidos sobre los fragmentos del torques de Cangas de Onís en relación con ele resto de la muestra. 
EsT. V

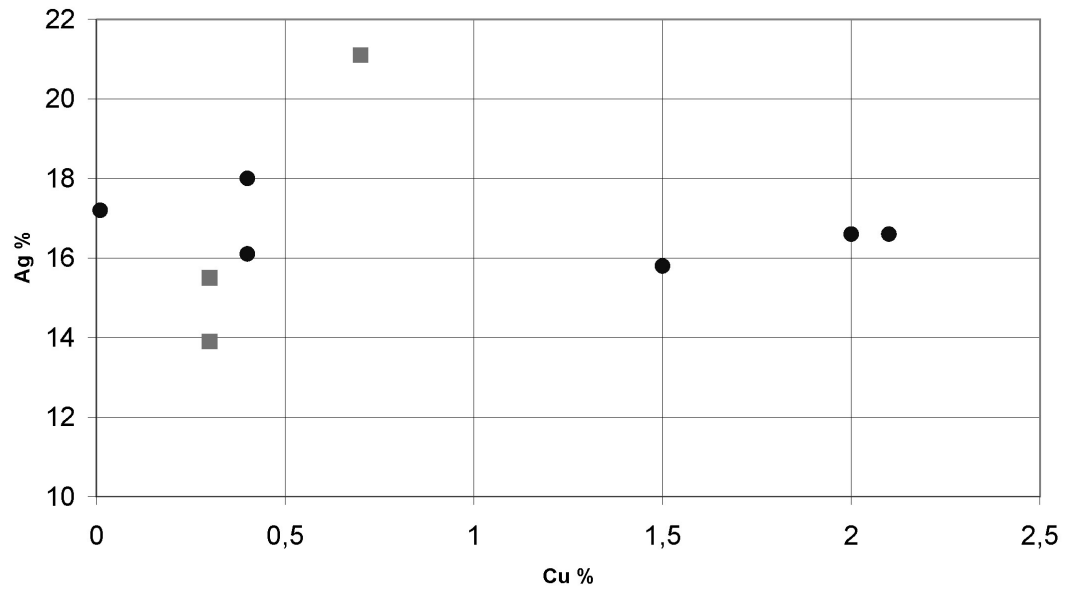

- 1972/113/1 = 1972/64/4

FIG. 1 - Variabilidad en la composición del oro de los torques

1972/113/1 y 1972/64/4.

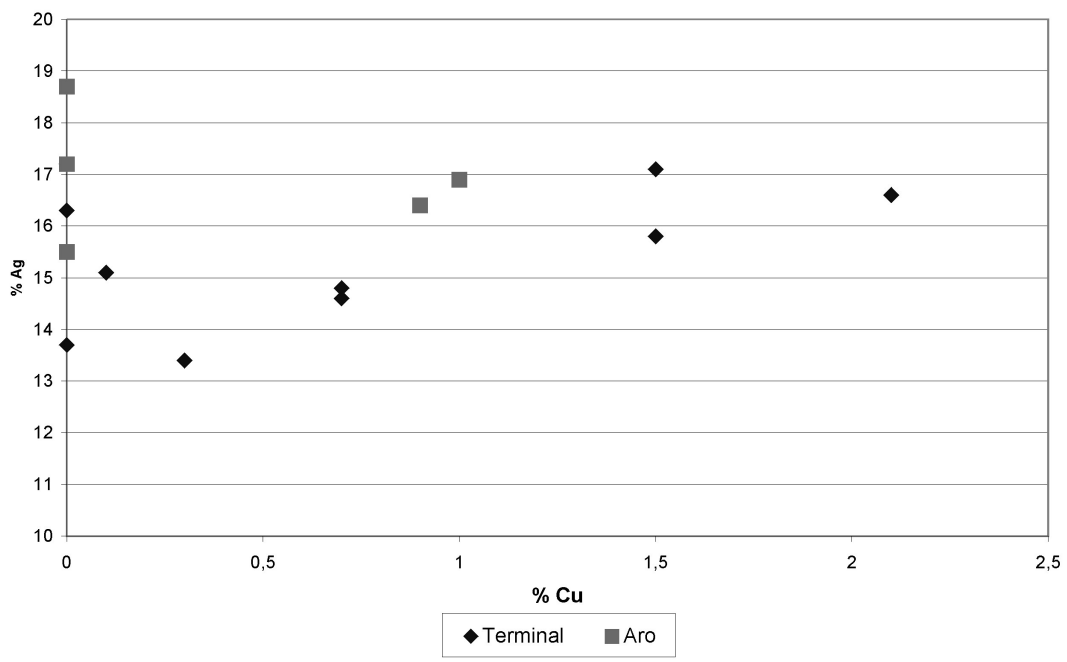

FIG. 2 - Comparación de las composiciones de aros y terminales de los torques analizados. 